\title{
Bronchial hyperreactivity and spirometric impairment in patients with allergic rhinitis
}

\author{
I. Cirillo1, A. Vizzaccaro1, M.A. Tosca2 , S. Negrini3, \\ A.C. Negrini4, G. Marseglia5, G. Ciprandi6
}

ABSTRACT: Bronchial hyperreactivity and spirometric impairment in patients with allergic rhinitis. I. Cirillo, A. Vizzaccaro, M.A. Tosca, S. Negrini, A.C. Negrini, G. Marseglia, G. Ciprandi.

Background: The Link between allergic rhinitis and asthma is well known. Bronchial hyperreactivity (BHR) may be present in rhinitics. The present study is aimed at evaluating a large group of subjects suffering from allergic rhinitis alone to investigate the presence of spirometric impairment and BHR both during and outside the pollen season.

Methods: 360 rhinitics (subdivided in 3 groups: seasonal, SAR, perennial, PAR, and polysensitized, PolysR) were investigated by spirometry and methacholine challenge.

Results: There was a significant seasonal difference concerning the number of rhinitics with impaired $\mathrm{FEV}_{1}(\mathbf{p}<0.01$ for $S A R, p<0.02$ for PAR, and $p<0.03$ for PolysR) and $F_{E F} F_{25-75}$ $(p<0.05$ for $S A R, p<0.03$ for $P A R$, and $p<0.05$ for PolysR) as well as with BHR ( $<<0.05$ for $S A R$ and $p<0.03$ for PAR).

Conclusions: This study evidences that an impairment of spirometric parameters and BHR may be observed in patients with allergic rhinitis alone. Thus, careful evaluation of lower airways should be performed in patients with allergic rhinitis alone.

Monaldi Arch Chest Dis 2005; 63: 2, 79-83.

Keywords: Seasonal allergic rhinitis, perennial allergic rhinits, polysensitized patients, bronchial hyperreactivity, methacholine challenge, bronchial obstruction.

1 Ospedale Principale della Marina Militare, Reparto di Medicina, Allergologia e Fisiopatologia Respiratoria, La Spezia,

2 Istituto Giannina Gaslini, Genova,

3 Dipartimento di Medicina Interna, Università di Genova,

4 Primario Emerito di Allergologia, Ospedale San Martino di Genova,

5 Clinica Pediatrica, IRCCS Policlinico San Matteo, Pavia,

6 Unità di Allergologia, Dipartimento Testa-Collo, Ospedale San Martino di Genova, Italy.

Correspondence: Giorgio Ciprandi; Allergologia; Dipartimento Regionale Testa-Collo; Padiglione Specialità; Ospedale San Martino; Largo R. Benzi 10, 16132 Genoa, Italy; e-mail: gio.cip@libero.it

\section{Introduction}

Allergic rhinitis is characterised by an inflammatory response of the nose induced by an IgEmediated reaction following allergen exposure [1].

Several studies demonstrated a close association between allergic rhinitis and asthma $[2,3,4$, 5]. In addition, we previously reported that $77 \%$ of conscripts with respiratory allergy suffered from asthma associated with allergic rhinitis [6). Moreover, allergic rhinitis has been demonstrated to be a strong risk factor for the onset of asthma in adults [7].

Asthma is characterised by a reversible airflow obstruction and forced expiratory volume/1 second $\left(\mathrm{FEV}_{1}\right)$ is considered the main parameter to evaluate bronchial obstruction [8]. Nevertheless, there is increasing interest in the consideration of the involvement of small airways in the pathogenesis of asthma [9]. Even though, there is no direct parameter able of assessing small airways, it has been assumed that the forced expiratory flow at the 25 and $75 \%$ of the pulmonary volume $\left(\mathrm{FEF}_{25-75}\right)$ might be considered as a measure of the caliber concerning distal airways [10]. Particularly, subjects with mild asthma and normal $\mathrm{FEV}_{1}$ may show impaired $\mathrm{FEF}_{25-75}$ only [11].

On the other hand, bronchial hyperreactivity (BHR) is a paramount feature of asthma. Moreover, BHR may be observed in a proportion of rhinitics [12]. In this regard, it has been hypothesized that a positive bronchial challenge to methacholine could be considered as predictive for those rhinitics would progress to develop asthma [13]. BHR was reported both in patients with perennial allergic rhinitis and in subjects with seasonal allergic rhinitis [14]. In addition, a seasonal variability in BHR was described in subjects sensitized to pollens [15]. Very recently, we demonstrated that $48 \%$ of patients with perennial allergic rhinitis alone showed initial bronchial obstruction, as provided by reduced $\mathrm{FEF}_{25-75}$ values, [16] and $72 \%$ of them had positive methacholine challenge [16].

On the basis of these considerations, we hypothetised that rhinitics may present different spirometric and BHR patterns both concerning etiology 
and allergen exposure. Thus, we evaluated a large group of patients with allergic rhinitis alone, subdividing them in 3 groups: patients with perennial allergic rhinitis (PAR), with seasonal allergic rhinitis (SAR), and with allergic rhinitis due to polysensitization (PolysR). Thus, we aimed at investigating the presence of BHR and spirometric abnormalities in these patients both during and outside the pollen season. Therefore, this study may be considered new and original concerning both large number of patients and timing of observation.

\section{Materials and methods}

\section{Study design}

The study was performed during and outside the pollen season. To evaluate spirometric abnormalities and the presence of BHR in patients with pure allergic rhinitis, we included subjects with sensitisation to pollens, perennial allergens or both kinds of allergens. We excluded all the subjects who met the following exclusion criteria: asthma symptoms, including cough, wheezing, dyspnoea, and shortness of breathing, previous or current smoking, acute upper respiratory infections and use of nasal or oral corticosteroids, and antihistamines within the previous 4 weeks.

The study was approved by the Navy Hospital Institutional Review Board and an informed consent was obtained from patients.

\section{Subjects}

Three hundred sixty rhinitic patients were prospectively and consecutively evaluated, all males, age $26.7 \pm 5.3$ years. All of them were Navy soldiers who referred to Navy Hospital for periodic fitness visit. A detailed clinical history and a complete physical examination, including allergy evaluation, were performed. The diagnosis of allergic rhinitis was made on the basis of a history of nasal symptoms and positive skin prick test as described elsewhere [6].

All of them were evaluated performing both spirometry and methacholine bronchial challenge both during and outside pollen season.

The patients were included in the study on the basis of a clinical history of allergic rhinitis alone.

All patients had to be sensitised and on the basis of the kind of sensitisation we subdivided them in three groups:

a) 120 subjects sensitised to pollens only, SAR group;

b) 120 subjects sensitised to perennial allergens only, PAR group;

c) 120 subjects sensitised both to pollens and perennial allergens, PolysR group.

The most relevant pollen allergens are in our geographic area: Parietaria officinalis, grasses, olive tree, birch, and hazel [6].

The most important perennial allergens are in our geographic area: house dust mites (i.e. Dermatophagoides farinae and pteronyssinus), cat and $\operatorname{dog}[6]$.

\section{Skin prick test}

It was performed, as stated by the Italian Society of Allergy and Clinical Immunology [17]. The panel consisted of: house dust mites (Dermatophagoides farinae and pteronyssinus), cat, dog, grasses mix, Compositae mix, Parietaria officinalis, birch, hazel, olive tree, Alternaria tenuis, Cladosporium, Aspergilli mix (Stallergenes, Milan, Italy).

\section{Spirometry}

It was performed by using a computer-assisted spirometer (COSMED, Eurasem, Italy), with optoelectronic whirl flow meter. Spirometry is performed as stated by ERS [18], using the European Community for Steel and coal (ECSC) reference equations.

If an airway obstruction was present as detected by $\mathrm{FEV}_{1}$ values less than $80 \%$ of the predicted, a test of bronchodilatation was performed using a salbutamol metered dose of $200 \mathrm{mcg}$. Reversibility was considered if an increase of at least $12 \%$ of $\mathrm{FEV}_{1}$ from baseline was achieved, according to international guidelines [19].

\section{Methacholine bronchial challenge}

It was performed to evaluate BHR only if basal $\mathrm{FEV}_{1}$ was equal or more than $80 \%$ of predicted. Aerosol is delivered using a dosimetric computerised supply (MEFAR MB3, Marcos, Italy). Subjects inhaled increasing doses of methacholine, starting from $34 \mu \mathrm{g} / \mathrm{mL}$. The scheduled doses consisted of the following: $34,68,68,68,68,170$, $170,340,170,340,170 \mu \mathrm{g} / \mathrm{mL}$ as previously reported $[6,16]$.

The test was interrupted when $\mathrm{FEV}_{1}$ value was reduced by more or equal than $20 \%$ of control or a maximal cumulative dose of $1,590 \mu \mathrm{g} / \mathrm{ml}$ was achieved. The threshold dose causing a $20 \%$ fall of $\mathrm{FEV}_{1}\left(\mathrm{PD}_{20} / \mathrm{FEV}_{1}\right)$ was calculated.

\section{Statistical analysis}

Statistical analysis was performed using $\mathrm{X}$ square test, calculating confidential limits of the relative risk at $95 \%$. Differences were considered significant if $p$ values were $<0.05$. Data is presented as means \pm standard deviation.

\section{Results}

All rhinitics were consecutive subjects for each group, meeting the inclusion and exclusion criteria, and agreeing to join the study.

No adverse event was reported during the study.

\section{During pollen season findings}

Spirometry: Four SAR patients, 5 PAR, and 6 PolysR showed FEV 1 value less than $80 \%$ of the predicted (figure 1). It has to be mentioned that all 


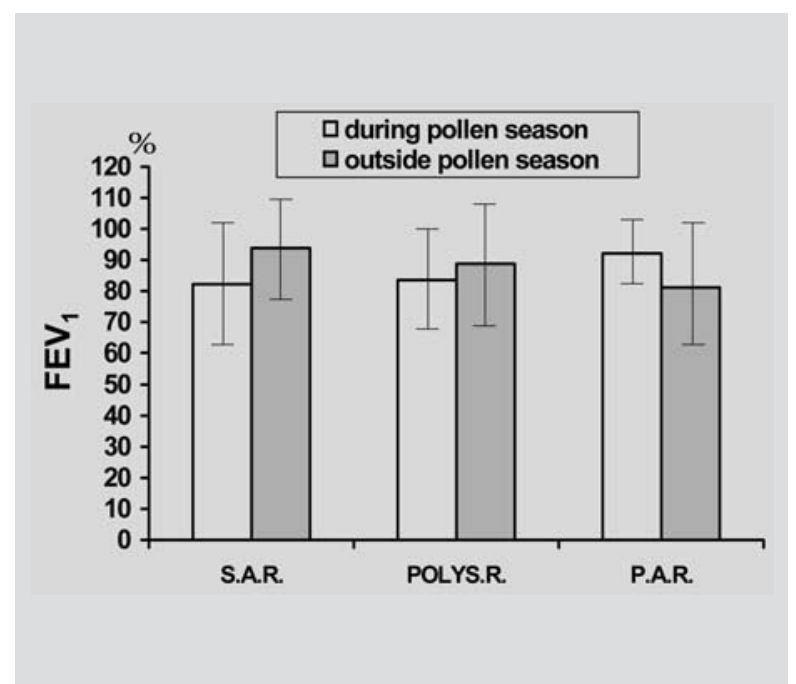

Fig. 1. - FEV 1 values (as \% of predicted) during (white bars) and outside (grey bars) the pollen season in patients with seasonal allergic rhinitis (SAR), in polysensitised rhinitics (PolysR), and in patients with perennial allergic rhinitis (PAR)

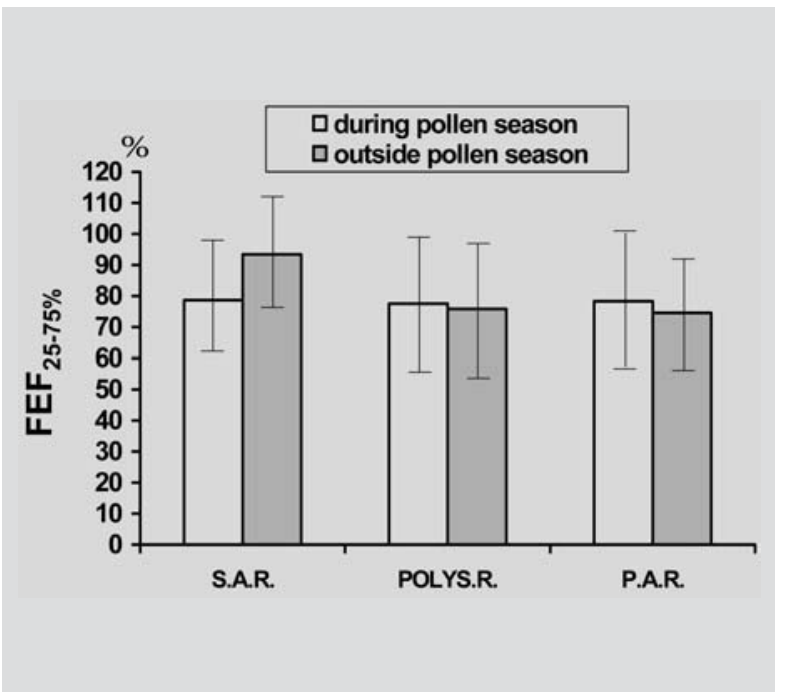

Fig. 2. - $\mathrm{FEF}_{25-75}$ values (as \% of predicted) during (white bars) and outside (grey bars) the pollen season in patients with seasonal allergic rhinitis (SAR), in polysensitised rhinitics (PolysR), and in patients with perennial allergic rhinitis (PAR)

of them were completely symptomless for complaints concerning lower airways. A bronchial reversibility was achieved in all subjects.

Then, we evaluated the distribution of the patients considering FVC values and $\mathrm{FEF}_{25-75}$ values (figure 2). Eight SAR patients, 7 PAR patients, and 7 PolysR patients showed impaired FVC values (i.e. $<80 \%$ of predicted). Seventeen SAR patients, 29 PAR patients, and 28 PolysR patients showed reduced $\mathrm{FEF}_{25-75}$ values (i.e. $<80 \%$ of predicted).

Methacholine bronchial challenge: it was performed in rhinitics with $\mathrm{FEV}_{1}$ values $\geq 80 \%$ of predicted. Sixty-five SAR patients, 92 PAR patients, and 79 Polys patients showed a positive methacholine challenge (figure 3 ).

$\mathbf{P D}_{20} / \mathbf{F E V}_{1}$ methacholine: the means $\pm \mathrm{sd}$ were: $352 \pm 331 \mathrm{mcg} / \mathrm{mL}$ in SAR patients, 268 $\pm 205 \mathrm{mcg} / \mathrm{mL}$ in PAR patients, and $242 \pm 220$ in PolysR patients (figure 4 ).

\section{Outside pollen season findings}

Spirometry: No SAR patient, 15 PAR, and 12 PolysR showed a FEV 1 value less than $80 \%$ of the predicted (figure 1). Five SAR patients, 10 PAR, and 5 PolysR showed reduced FVC values. Eleven SAR patients, 38 PAR, and 34 PolysR showed impaired $\mathrm{FEF}_{25-75}$ values (figure 2).

Methacholine bronchial challenge: Fiftyfive SAR patients, 96 PAR, and 91 PolysR showed a positive methacholine challenge (figure 3 ).

$\mathbf{P D}_{20} / \mathbf{F E V}_{1}$ methacholine: the means $\pm \mathrm{sd}$ were: $448 \pm 427 \mathrm{mcg} / \mathrm{mL}$ in SAR patients, 210 $\pm 192 \mathrm{mcg} / \mathrm{mL}$ in PAR patients, and $220 \pm 210$ in PolysR patients (figure 4).

\section{During versus outside pollen season findings}

Spirometry: There was a significant difference concerning the number of rhinitics with abnormal $\mathrm{FEV}_{1}$ values:

- SAR group 4 vs $0(\mathrm{p}<0.01)$

- PAR group 5 vs $15(\mathrm{p}<0.02)$,

- PolysR group 6 vs 12 ( $<<0.03)$.

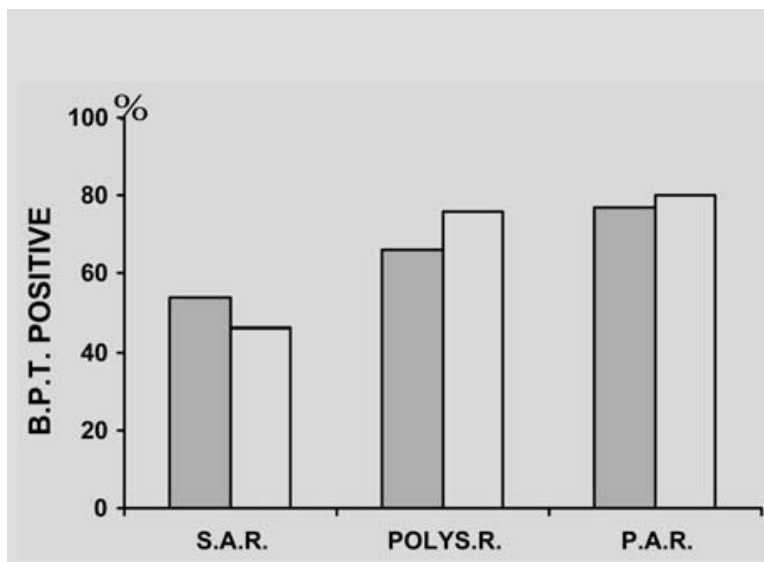

Fig. 3. - Percentage distribution of BHR positive patients during (grey bars) and outside (white bars) the pollen season in patients with seasonal allergic rhinitis (SAR), in polysensitised rhinitics (PolysR), and in patients with perennial allergic rhinitis (PAR).

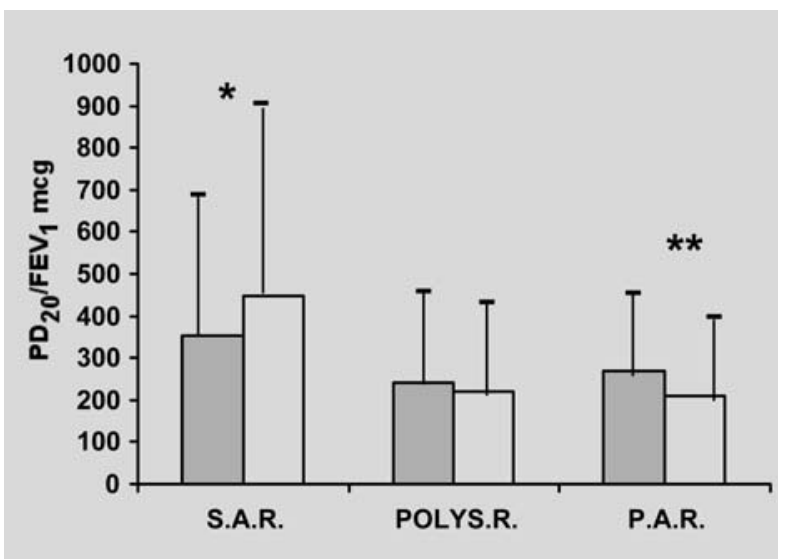

Fig. 4. - Means \pm sd of $\mathrm{PD}_{20} / \mathrm{FEV}_{1}$ methacholine during (grey bars) and outside (white bars) the pollen season in patients with seasonal allergic rhinitis (SAR), in polysensitised rhinitics (PolysR), and in patients with perennial allergic rhinitis (PAR). 
No significant difference was demonstrated for FVC values.

Concerning $\mathrm{FEF}_{25-75}$ values, there was a significant difference between the two observation times:

- SAR group 17 vs $11(\mathrm{p}<0.05)$,

- PAR group 29 vs $38(\mathrm{p}<0.03)$,

- PolysR group 28 vs 34 ( $\mathrm{p}<0.05)$.

Methacholine bronchial challenge: There were significant differences concerning the mean methacholine $\mathrm{PD}_{20} / \mathrm{FEV}_{1}$ in:

- SAR group $(\mathrm{p}<0.05)$,

- PAR group $(\mathrm{p}<0.03)$.

\section{Discussion}

Allergic rhinitis and asthma should be considered as a single syndrome involving two parts of the respiratory tract [20]. The pathophysiology of allergic rhinitis is similar to that of asthma and their responses to pharmacological and specific immunological interventions are comparable (21). Allergic rhinitis may contribute to worsen asthma through different pathophysiologic mechanisms: post-nasal drip, nasal-bronchial reflex, oral breathing, and systemic allergic inflammation [19].

Allergic rhinitics frequently present a non-specific BHR even in absence of asthmatic symptoms. In these subjects with normal $\mathrm{FEV}_{1}$ values, BHR may be envisaged as a marker of susceptibility to develop asthma.

Thus, we aimed at investigating a larger group of patients with allergic rhinitis, considering the kind of sensitisation and the period of observation (i.e. both during and outside the pollen season).

The present findings suggest some considerations concerning the link between upper and lower airways and the variations of respiratory parameters consequent on allergen exposure.

Firstly, evaluating a large cohort of subjects with allergic rhinitis alone, it is possible to single out some subjects with overt bronchial obstruction, as documented by impaired $\mathrm{FEV}_{1}$ values, both during and outside the pollen season. These patients may be considered as "poor perceiver" of their lower respiratory symptoms. In fact, all of them had a normal life playing different sports without trouble. In addition, they never felt lower respiratory symptoms nor diagnosis of asthma has been made. In addition, it has to be highlighted that no subject belonging to SAR group showed overt bronchial obstruction outside the pollen season. This issue confirms the close relationship between pollen exposure and asthma appearance in those patients. On the other hand, the number of patients with overt bronchoconstriction was more evident in PAR and PolysR goups outside the pollen season. This remark is related to increased amount of mites during the fall-winter period. Thus, there is a close relationship between the level of allergen exposure and bronchial airflow impairment.

Secondly, most of our rhinitics showed BHR. This finding is not surprising if compared with literature analysis. Even in this case, the relationship between the period of allergen exposure and BHR is demonstrated. The exposure to allergens is characterised by nasal inflammation as previously described by us [22]. This concept may be consistent with consequent bronchial inflammation [23]. The $\mathrm{PD}_{20} / \mathrm{FEV}_{1}$ methacholine significantly increased outside the pollen season in SAR patients and in PAR group. This point further remarks on the close connection between BHR and allergen exposure.

Thirdly, considering the evaluation of $\mathrm{FEF}_{25-75}$ parameter we demonstrated that some rhinitics show an initial level of bronchial obstruction. It is noteworthy that this percentage diminishes outside the pollen season in SAR patients, but does not completely disappear. This issue is consistent with the concept that chronic bronchial inflammation as well as BHR may persist also in absence of allergen exposure. Moreover, in PAR and PolysR patients this parameter appears more impaired outside the pollen season, confirming other data.

This data, taken together, highlights the link between upper and lower airways also in patients with allergic rhinitis alone.

Therefore, our data suggests that a new diagnostic approach should be carried out also in the patients with allergic rhinitis by carefully assessing lower airways. Thus, all rhinitics, even in absence of history suggesting for asthmatic symptoms, should be evaluated performing spirometry. Bronchial methacholine challenge may be considered as supplemental examination to achieve a more exhaustive evaluation in rhinitics. Moreover, rhinitics should be carefully followed up to evaluate the possible onset of asthma.

In conclusion, our study underlines the frequent coexistence of bronchial impairment and BHR in those patients with allergic rhinitis alone and supports the strong link between upper and lower airways.

\section{References}

1. Van Cauwenberger P, De Belder T, Vermeiren J, Kaplan A Global resources in allergy (GLORIA): allergic rhinitis and conjunctivitis. Clin Exp All Rev 2003; 3: 46-50.

2. Johansson SGO, Hourihane JO'B, Bousquet $\mathrm{J}$ et al. A revised nomenclature for allergy. An EAACI position statement from the EAACI nomenclature task force. $\mathrm{Al}$ lergy 2001; 56: 813-24.

3. Pederson PA, Weeke ER Asthma and allergic rhinitis in the same patients. Allergy 1983; 38: 25-9.

4. Settipane GA Allergic rhinitis- update. Otolaryngol Head Neck Surg 1986; 94: 470-5.

5. Beasly R ISAAC-Phase I results: global comparison. Eur Resp Soc 1997 (Abstract).

6. Ciprandi G, Vizzaccaro A, Cirillo I et al. Increase of asthma amd allergic rhinitis prevalence in young Italian men. Int Arch Allergy Immunol 1996; 111: 279-83.

7. Plaschke PP, Janson C, Norrman E et al. Onset and remission of allergic rhinitis and asthma and the relationship with atopic sensitization and smoking. Am J Respir Crit Care 2000; 162: 920-4.

8. Beers MH, Berkow R, eds The Merck manual of diagnosis and therapy. 17th edn. Whitehouse Station, NJ: Merck Research Laboratories, 1999; 521-32.

9. Hamid Q, Song Y, Kotsimbos TC et al. Inflammation of small airways in asthma. J Allergy Clin Immunol 1997; 100: 44-51. 
10. Bjermer L Past and future perspectives in the asthma treatment. Resp Med 2001; 95: 703-19.

11. Lipworth BJ, Clark DJ Effects of airway calibre on lung delivery of nebulised salbutamol. Thorax 1997; 52: 1016-23.

12. Katelaris $\mathrm{CH}$ Allergic rhinitis and asthma: epidemiological evidence for the link. Clin Exp All Rev 2003; 3: 5-8.

13. Townley RG, Ryo UY, Kolotkin BM, Kang B Bronchial sensitivity to methacholine in current and former asthmatic and allergic rhinitis patients and control subjects. J Allergy Clin Immunol 1975; 56: 429-42.

14. Braman SS, Barrows AA, DeCotis BA et al. Airways hyper-responsiveness in allergic rhinitis. A risk factor for asthma. Chest 1987; 91: 671-4.

15. Verdiani P, Di Carlo S, Baronti A Different prevalence and degree of nonspecific bronchial hyperreactivity in rhinitis. J Allergy Clin Immunol 1990; 86: 576-82.

16. Ciprandi G, Cirillo I, Tosca MA, Vizzaccaro A Bronchial hyperreactivity and spirometric impairment in patients with perennial allergic rhinitis. Int Arch Allergy Immunol 2004; 133: 14-8.
17. Società Italiana di Allergologia e Immunologia Clinica: "Memorandum della Diagnostica delle Allergopatie". Fed Med 1987; 40: 861-874.

18. Quanjer, $\mathrm{PhH}$, Tammeling GJ, Cotes JE, Pedersen OF, Peslin R, Yernault J-C. Standardized lung function testing. Eur Respir J 6: 1-99, 1993.

19. Global Initiative for Asthma. Pocket Guide for Asthma Management and Prevention. National Hearth, Lung and Blood Institute, National Institute of Health, Bethesda, MD, 1997, NIH Publication no. 96-3659B.

20. Simons FER What's in a name? The allergic rhinitisasthma connection. Clin Exp All Rev 2003; 3: 9-17.

21. Guerra S, Sherrill DL, Martinez FD, Barbee RA Rhinitis as an independent risk factor for adult-onset asthma. J Allergy Clin Immunol 2002; 109: 419-25.

22. Ciprandi G, Pronzato C, Ricca V et al. Allergen-specific challenge induces ICAM-1 on nasal epithelial cells in allergic subjects. Am J Resp Crit Care 1994; 150: 1653-9.

23. Crimi E, Milanese M, Oddera S et al. Inflammatory and mechanical factors of allergen-induced bronchoconstriction in mild asthma and rhinitis. J Appl Physiol 2001; 91: 1029-1034.

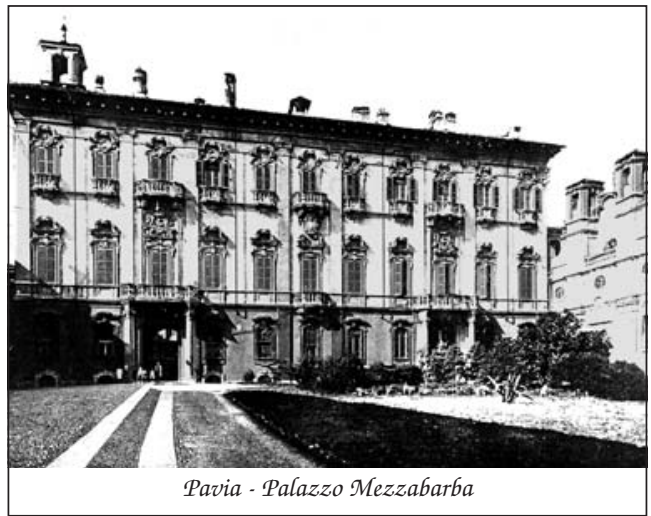

